\title{
Imposto de renda: matemática no cotidiano
}

\author{
Rubia Santos Maiara Marques
}

\section{Resumo}

Este trabalho tem por objetivo mostrar que o cálculo do imposto de renda mensal de uma pessoa física pode ser modelado através de uma função afim definida por partes.

Palavras-chave: Imposto de Renda; Função Afim; Alíquota; Parcela a Deduzir.

\begin{abstract}
This paper aims to show that the calculation of the monthly income tax of an individual can be modeled through an affine function defined by parts.
\end{abstract}

Keywords: Income Tax; Affine Function; Aliquot; Deduction.

\section{Introdução}

A matemática encontra-se cada dia mais presente no cotidiano. O uso de problemas em sala de aula proporciona ao aluno uma aproximação dos conteúdos abordados com a prática. O presente artigo é parte de uma dissertação de mestrado desenvolvida no âmbito do Programa de Mestrado Profissional em Matemática (Profmat) da Universidade Federal de Mato Grosso do Sul. Na RPM revista do professor de matemática encontra-se uma outra abordagem sobre imposto de renda proposta por [2].

O imposto de renda é um tributo cobrado anualmente sobre os rendimentos de uma pessoa física ou jurídica. Para calcular o valor do imposto a ser pago por uma pessoa física, desconta-se do total de vencimentos a contribuição previdenciária e as deduções legais; por exemplo: dependentes declarados. Ao valor obtido após as deduções, chamado de base de cálculo para o imposto de renda, aplica-se a alíquota, que é a taxa percentual incidente sobre a base de cálculo.

A alíquota que deve ser aplicada a cada faixa salarial é determinada de acordo com a tabela de incidência mensal do IRPF determinada pela Receita Federal, de modo que o imposto a ser pago varie continuamente com a renda. Desde o ano de 2015, a tabela de incidência mensal [3] para cálculo do imposto sobre a renda das pessoas físicas permanece a mesma, veja Tabela 1. 
Tabela 1: Incidência mensal para cálculo do imposto sobre a renda das pessoas físicas

\begin{tabular}{ll}
\hline Base de cálculo $(\mathrm{R} \$)$ & Alíquota $(\%)$ \\
\hline Até 1903,98 & - \\
De 1903,99 até 2826,65 & 7,5 \\
De 2826,66 até 3751,05 & 15 \\
De 3751,06 até 4664,68 & 22,5 \\
Acima de 4664,68 & 27,5 \\
\hline
\end{tabular}

Fonte: Receita Federal do Brasil

\subsection{Construindo a função}

Como o imposto mensal devido deve variar continuamente com a renda, o seu cálculo deve ser feito separando-se a base de cálculo nas faixas determinadas na Tabela 1 e aplicando a alíquota referente a cada faixa [1]. Assim, considerando $x$ a base de cálculo para o imposto de renda e $a$ a alíquota a ser aplicada, o imposto mensal $I$ a ser pago pode ser calculado da seguinte forma:

1. Para um salário com base de cálculo $x$ de $\mathrm{R} \$ 1903,99$ a $\mathrm{R} \$ 2826,65$, desconta-se a parcela isenta de $\mathrm{R} \$ 1903,98$ e, ao resultado, aplica-se a alíquota de 7,5 \%. Logo:

$$
I(x)=0,075 \cdot(x-1903,99)=0,075 x-142,80
$$

2. Considerando $2826,66 \leq x \leq 3751,05$, deve-se aplicar a alíquota de 7,5\% à $\mathrm{R} \$ 922,66$ referente à parte da base de cálculo que se encontra na faixa de $\mathrm{R} \$ 1903,99$ a $\mathrm{R} \$ 2826,65$, subtrair de $x$ a parcela isenta de $\mathrm{R} \$ 1903,98$ e a parcela de $\mathrm{R} \$ 922,66$ e, à diferença, empregar a alíquota de $15 \%$ adicionando os resultados encontrados. Portanto:

$$
I(x)=0,075 \cdot 922,66+0,15 \cdot(x-1903,98-922,66)=0,15 x-354,80
$$

3. Analogamente, se $3751,06 \leq x \leq 4664,68$, tem-se que:

$$
I(x)=0,075 \cdot 922,66+0,15 \cdot 924,39+0,225 \cdot(x-1903,98-922,66-924,39)=0,225 x-636,13
$$

4. E, por fim, se $x>4664,68$ então:

$$
\begin{aligned}
I(x)= & 0,075 \cdot 922,66+0,15 \cdot 924,39+0,225 \cdot 913,62+ \\
& 0,275 \cdot(x-1903,98-922,66-924,39-913,62) \\
I(x)= & 0,275 x-869,36
\end{aligned}
$$

Portanto, o imposto de renda mensal a ser pago para uma base de cálculo qualquer pode ser definido através da função $I: \mathbb{R}^{+} \rightarrow \mathbb{R}$ dada por

$$
I(x)=\left\{\begin{array}{lll}
0, & \text { se } \quad x<1903,99, \\
0,075 x-142,8, & \text { se } \quad 1903,99 \leq x<2826,65, \\
0,15 x-354,8, & \text { se } 2826,65 \leq x<3751,05 \\
0,225 x-636,13, & \text { se } 3751,05 \leq x \leq 4664,68 \\
0,275 x-869,36, & \text { se } x>4664,68 .
\end{array}\right.
$$


Os valores fixos que são subtraídos em cada intervalo são chamados de parcela a deduzir do imposto. Esses valores já ficam predeterminados na tabela de incidência mensal para cálculo do imposto sobre a renda das pessoas físicas fornecida pela Receita Federal do Brasil.

Em cada intervalo de $x$ o gráfico de $I(x)$ é uma reta, com uma inclinação específica. Os extremos $x$ de cada intervalo satisfazem a igualdade da faixa anterior e da faixa a que pertencem, por isso essas retas ficam ligadas umas às outras. Na Figura 1 é possível observar uma representação gráfica da função $I(x)$.

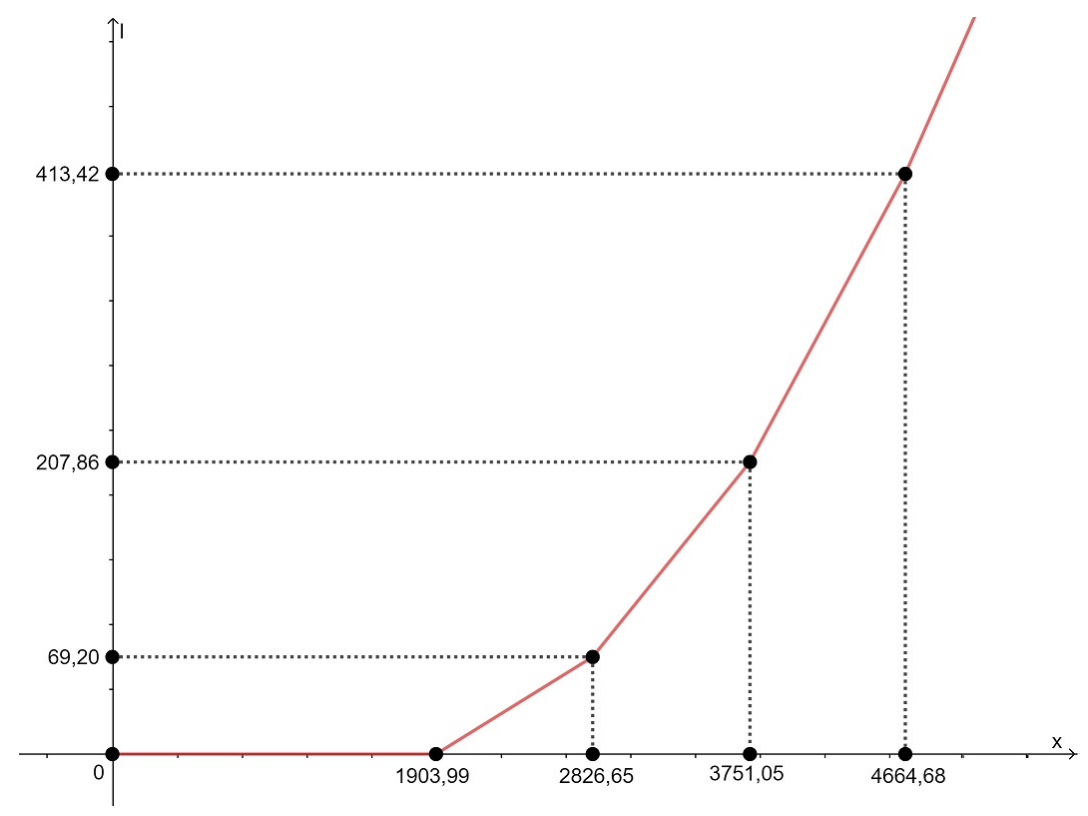

Figura 1: Gráfico da função $I$.

Pode-se concluir que o imposto de renda mensal devido por uma pessoa física pode ser calculado através de uma função definida em partes, onde em cada intervalo o valor de $I$ é determinado através de uma função afim.

\subsection{Exemplos}

1. Um professor de Matemática efetivo da Rede Municipal de Ensino de Campo Grande/MS com carga horária de $20 \mathrm{~h}$ semanais cujo vencimento base é de $\mathrm{R} \$ 3595,90$. Sabendo que a contribuição previdenciária mensal desse indivíduo é de $\mathrm{R} \$ 368,98$ e que não possui dependentes legais, a base de cálculo para o imposto de renda desse professor é de $\mathrm{R} \$ 3595,90-\mathrm{R} \$ 368,98=\mathrm{R} \$ 3226,92$. Conforme a Tabela 1, nota-se que a essa base de cálculo de $\mathrm{R} \$ 3226,92$ corresponde a alíquota de $\mathbf{1 5 \%}$ e de acordo com a função $I(x)$ encontra-se no intervalo 2826, $66 \leq x \leq 3751,05$. Assim, o imposto de renda mensal devido por esse professor é dado por:

$$
I(x)=0,15 x-354,8=0,15 \cdot 3226,92-354,8=129,24
$$


2. Seja $\mathrm{R} \$ 5288,05$ o vencimento base de um professor de Matemática efetivo do Instituto Federal de Mato Grosso do Sul com carga horária de 40h semanais em regime de dedicação exclusiva. Sendo $\mathrm{R} \$ 581,68$ a contribuição previdenciária mensal desse professor e sabendo que o mesmo não possui dependentes legais, então a base de cálculo para o imposto de renda é de $\mathrm{R} \$ 5288,05-\mathrm{R} \$$ $581,68=\mathrm{R} \$ 4706,37$. De acordo com a Tabela 1 , a essa base de cálculo corresponde a alíquota de $\mathbf{2 7 , 5 \%}$ e, observando a função $I(x)$, vê-se que $\mathrm{R} \$ 4706,37$ encontra-se no intervalo $x>4664,68$. Logo, o imposto de renda mensal a ser pago por esse indivíduo pode ser assim obtido:

$$
I(x)=0,275 x-869,36=0,275 \cdot 4706,37-869,36=424,89
$$

\section{Referências}

[1] Marques, M. N. B. Funções Reais e Funções Convexas. Dissertação de Mestrado Profmat, 2018.

[2] Colli, E. Imposto Progressivo. Revista do Professor de Matemática, Rio de Janeiro, Volume 54, p. 11-12, 2004.

[3] RECEITA FEDERAL DO BRASIL. IRPF (Imposto sobre a renda das pessoas físicas). Disponível em: <http://idg.receita.fazenda.gov.br/acesso-rapido/tributos/irpf-imposto-de-rendapessoa-fisica\#calculo_mensal_IRPF $>$ Acesso em: 10 set. 2018

Rubia Santos

Instituto de Matemática Universidade Federal de Mato Grosso do Sul <rubia.oliveira@ufms.br>

Maiara Marques

Mestrado Profissional em Matemática em Rede Nacional $<$ maiara.nborges@gmail.com>

Recebido: 11/02/2019 